\title{
Use of Distal Intracranial Catheters for Better Working View of Cerebral Aneurysms Hidden by Parent Artery or Its Branches: A Technical Note
}

\author{
Ehab Mahmoud, MD, PhD, Samuel Lenell, MD, Christoffer Nyberg, MD, PhD, Ljubisa Borota, MD, PhD \\ Department of Surgical Sciences, Uppsala University Hospital, Uppsala, Sweden
}

\begin{abstract}
A good working view is critical for safe and successful endovascular treatment of cerebral aneurysms. In a few cases, endovascular treatment of cerebral aneurysms may be challenging due to difficulty in obtaining a proper working view. In this report of 6 cases, we described the advantage of using a distal intracranial catheter (DIC) to achieve better visualization of cerebral aneurysms hidden by a parent artery or its branches. Between September 2017 and January 2021, we treated 390 aneurysms with endovascular techniques. In 6 cases in which it was difficult to obtain a proper working view, the DIC was placed distally close to the aneurysm in order to remove the parent artery projection from the working view and obtain better visualization of the aneurysm. Clinical and procedural outcomes and complications were evaluated. The position of the DIC was above the internal carotid artery siphon in the 6 cases. All aneurysms were successfully embolized. Raymond-Roy class 1 occlusion was achieved in all 4 unruptured aneurysms, while the result was class 2 in the 2 ruptured aneurysms. Placement of the DIC was atraumatic without dissections or significant catheter-induced vasospasm in all patients. Transient dysphasia was seen in 2 cases and transient aphasia in 1. Using this technique, we have found it possible to better visualize the aneurysm sac or neck and thereby treat cases we otherwise would have considered untreatable.
\end{abstract}

Key Words: Aneurysm; Intracranial aneurysm; Cerebral angiography; Endovascular techniques; Neuroimaging

\section{INTRODUCTION}

Endovascular coil embolization of intracranial aneurysms requires 2-dimensional $X$-ray images, known as working views, to visualize the aneurysm sac and neck during coiling. A good working view during endovascular treatment of cerebral aneurysms is essential to achieving successful occlusion of the aneurysm. Failure to obtain an adequate working view may result in unsuccessful results, like coil placement in the parent artery, aneurysm perforation, or failure to occlude the aneurysm properly. ${ }^{1}$ Despite improvement in 3-dimensional (3D) digital subtraction angiography in mapping and obtaining a proper working view for endovascular treatment of intracranial aneurysms, some cases pose challenges in obtaining a proper working view. ${ }^{1-3}$ Distal intracranial catheters (DICs) are a newer generation of distal guide and access catheters that have

\section{Correspondence to:} Ehab Mahmoud, MD, PhD Department of Surgical Sciences, Uppsala University Hospital, Akademiska Sjukhuset, BFC, 75185 Uppsala, Sweden Tel: +46723864330 Fax: +4618510865 E-mail:ehab.mahmoud@akademiska.se Received: May 31, 2021 Revised: August 24, 2021 Accepted: September 8, 2021

Copyright $\odot 2021$ Korean Society of Interventional Neuroradiology This is an Open Access article distributed under the terms of the Creative Commons Attribution Non-Commercial License (http://creativecommons.org/licenses/by-nc/4.0) which permits unrestricted non-commercial use, distribution, and reproduction in any medium, provided the original work is properly cited.

pISSN 2093-9043 eISSN 2233-6273 
soft distal ends, thereby allowing the catheter to navigate further into the intracranial circulation. DICs are used to treat various cerebrovascular pathologies, including intracranial aneurysms, to achieve stable and better control of microcatheters. ${ }^{4-13}$ In our 6 cases, we selected the best working projection from the 3D rotational angiography, but during injection into the guiding catheter in the parent vessel, we were not able to visualize the aneurysm sac and neck properly. We found that placement of the DIC intracranial close to the aneurysm contributes significantly to better visualization of aneurysms and consequently to technically easier intervention with better radiological results and clinical outcomes.

\section{MATERIALS AND METHODS}

At our institution, coil embolization for intracranial aneurysms is performed using a standard coaxial system. Since June 2017, we have used DICs in several neurointerventional procedures. The DIC was used to overcome anticipated difficulties by stabilizing the microcatheter during coiling in cases with parent vessel tortuosity.

In these reported cases, we treated 6 aneurysms in 6 patients. In all these cases, DICs were used not only for achieving stability and better control of microcatheters, but also for obtaining better visualization of the aneurysm. Two patients presented with subarachnoid hemorrhage (SAH) and were treated for ruptured aneurysms, and 4 patients were treated electively. The ruptured aneurysms were treated with coils alone; one of them with a balloon-assisted technique. The 4 unruptured aneurysms were treated with a stent and coils; 2 cases were treated with a Y-stenting technique, and the other 2 cases were treated with a single stent. The aneurysms were located in the anterior communicating artery (Acom, $\mathrm{n}=2$ ) and middle cerebral artery (MCA, $n=4$ ) (Table 1).

The safety and efficacy of using a DIC distally close to an aneurysm, procedural complications, and the obliteration of the aneurysms were retrospectively evaluated.

\section{Procedures and Interventions}

All radiological findings, technical details of interventions, complications, immediate and midterm radiological results, and midterm clinical outcomes are shown in Table 1.

All patients underwent a standard digital subtraction angiogram (DSA) and rotational angiography with 3D reconstructions to characterize aneurysm and parent artery anatomy. The best working views for endovascular treatment were deduced from 3D reconstructions. The aneurysm sac or neck was hidden by the parent artery or its branches in the best working view. Therefore, it was decided to put the DIC distally close to the aneurysm to avoid over-projection of the parent artery.

All procedures involved the use of a femoral $8 \mathrm{~F}$ artery sheath. A 6F AXS Infinity LS Long Sheath, 80 or 90 cm (Stryker

\section{Table 1. Radiological and clinical data}

\begin{tabular}{|c|c|c|c|c|c|c|c|c|c|c|}
\hline Patient & $\begin{array}{l}\text { Clinical } \\
\text { picture }\end{array}$ & $\begin{array}{c}\text { Aneurysm } \\
\text { location }\end{array}$ & Intervention & $\begin{array}{l}\text { Micro- } \\
\text { catheters }\end{array}$ & $\mathrm{DIC}$ & Complication & $\begin{array}{c}\text { DIC } \\
\text { position }\end{array}$ & $\begin{array}{l}\text { Immediate } \\
\text { radiological } \\
\text { result (RR) }\end{array}$ & $\begin{array}{l}\text { Midterm } \\
\text { follow-up } \\
\text { radiological } \\
\text { result (RR) }\end{array}$ & $\begin{array}{l}\text { Midterm } \\
\text { follow-up } \\
\text { clinical re- } \\
\text { sult (mRS) }\end{array}$ \\
\hline 1 & $\mathrm{SAH}$ & Acom & Coil & 1 & $\begin{array}{c}\text { Sofia } \\
\text { plus 6F }\end{array}$ & No & $\begin{array}{c}\text { Ant. } \\
\text { choroidal }\end{array}$ & 2 & 1 & 0 \\
\hline 2 & Incidental & MCA & Stent \& coil & 2 & $\begin{array}{c}\text { Sofia } \\
\text { plus 6F }\end{array}$ & $\begin{array}{l}\text { Transient } \\
\text { dysphasia }\end{array}$ & $\begin{array}{l}\text { Proximal } \\
\text { M1 }\end{array}$ & 1 & 1 & 0 \\
\hline 3 & Incidental & Acom & Stent \& coil & 2 & $\begin{array}{c}\text { Sofia } \\
\text { plus 6F }\end{array}$ & No & $\begin{array}{l}\text { Carotid } \\
\text { terminus }\end{array}$ & 1 & 1 & 0 \\
\hline 4 & Incidental & MCA & $\begin{array}{c}\text { Y-stent \& } \\
\text { coil }\end{array}$ & 2 & $\begin{array}{c}\text { Catalyst } \\
6 \mathrm{~F}\end{array}$ & $\begin{array}{c}\text { Transient } \\
\text { aphasia after } \\
8 \text { days }\end{array}$ & $\begin{array}{l}\text { Carotid } \\
\text { terminus }\end{array}$ & 1 & 1 & 0 \\
\hline 5 & Incidental & MCA & $\begin{array}{c}\text { Y-stent \& } \\
\text { coil }\end{array}$ & 2 & $\begin{array}{c}\text { Catalyst } \\
6 \mathrm{~F}\end{array}$ & $\begin{array}{l}\text { Transient } \\
\text { dysphasia }\end{array}$ & $\begin{array}{l}\text { Proximal } \\
\text { M1 }\end{array}$ & 1 & 1 & 0 \\
\hline 6 & $\mathrm{SAH}$ & Acom & $\begin{array}{c}\text { Balloon \& } \\
\text { coil }\end{array}$ & 2 & $\begin{array}{l}\text { Sofia } \\
\text { plus } 6 \mathrm{~F}\end{array}$ & No & $\begin{array}{c}\text { Proximal } \\
\text { A1 }\end{array}$ & 2 & 1 & 0 \\
\hline
\end{tabular}

RR, Raymond-Roy scale; mRS, modified Rankin Scale; DIC, distal intracranial catheter; SAH, subarachnoid hemorrhage; Acom, anterior communicating artery; MCA, middle cerebral artery; Ant., anterior. 
Neurovascular, Cork, Ireland) was placed proximally in the internal carotid artery. All interventions were performed with systemic heparinization; the patients initially received a bolus dose of 5,000 units of heparin, subsequently heparinized to more than twice the baseline activated clotting time. In patients with unruptured aneurysms, dual antiplatelet therapy was started with a loading dose of $180 \mathrm{mg}$ ticagrelor and $300 \mathrm{mg}$ aspirin the night before the intervention; then $90 \mathrm{mg}$ ticagrelor and $75 \mathrm{mg}$ aspirin were given on the morning day of the intervention. All of the devices were connected to a continuous flush of heparinized saline. To avoid vasospasm, 5 $\mathrm{mg}$ of the calcium channel blocker (nimodipin) was injected into the flush bag connected to the DIC.

A SOFIA (6F) Plus DIC, (MicroVention, Tustin, CA, USA) 0.070inch inner diameter (ID), $125 \mathrm{~cm}$ catheter was used in 4 cases. An AXS Catalyst 6 DIC (Stryker Neurovascular, Fremont, CA, USA) 0.060 -inch ID, $132 \mathrm{~cm}$ was used in 2 cases. All aneurysms were catheterized with a Headway 17 microcatheter (MicroVention), and a Traxcess 14 microwire (MicroVention) was used for coiling. A Headway Duo, $156 \mathrm{~cm}$ (MicroVention) microcatheter was used for deployment of the stent in 4 cases. A Scepter XC balloon (MicroVention) was used in the balloon-assisted procedure. Atlas Neuroform stents (Stryker Neurovascular) were used in 3 cases and a LVIS EVO stent (MicroVention) in 1 case. DICs were place in the terminus internal carotid artery (ICA, $n=2)$, proximal M1 segment $(n=2)$, proximal A1 segment $(n=1)$, and anterior choroidal artery level $(n=1)$ (Table 1). Placement of the DIC was atraumatic without dissections or significant catheter-induced vasospasm in all patients. Midterm follow-up results were evaluated 6 months after the treatment. Immediate and midterm radiological results were assessed using a modified Raymond-Roy scale, ${ }^{14}$ while clinical results were evaluated using a modified Rankin Scale (mRS).

\section{RESULTS}

\section{Immediate Angiographic Results}

All aneurysms were embolized successfully; the degree of embolization corresponding to Raymond-Roy class 1 in 4 unruptured aneurysms and class 2 in 2 ruptured aneurysms.

\section{Midterm Angiographic Follow-up Results}

At midterm follow-up, the degree of embolization of the aneurysms corresponded to Raymond-Roy class 1 in all 6 cases.

\section{Midterm Clinical Follow-up Results}

The clinical condition was classified as a 0 according to the mRS in all 6 cases.

\section{Complications}

We recorded 3 complications (Table 1). One patient (case 2), who was treated with a stent and coils, developed transient dysphasia after the treatment. Diffusion-weighted MR imaging revealed a lacunar infarction in the insular cortex on the ipsilateral side. One patient (case 5), who was treated with coils and 2 stents deployed in a "Y" configuration, developed dysphasia after the intervention. Postoperative computed tomography (CT) showed minimal subarachnoid bleeding in the left Sylvian fissure. Virtual non-contrast images from the dual-energy CT showed no subarachnoid bleeding, which means it was a contrast material extravasation, and contrast-induced encephalopathy was considered. The patient recovered completely within 2 days with steroid treatment. One patient (case 4), who was treated with coils and 2 stents deployed in " $Y$ " fashion, developed transient aphasia 8 days after the procedure and a CT scan revealed neither hemorrhage nor infarct.

\section{Representative Cases}

\section{Case 1}

A patient presented with acute headache, seizure attack, and vomiting. A non-contrast CT scan showed a widespread $\mathrm{SAH}$, and a CT angiogram revealed an Acom aneurysm consistent with the hemorrhage. An external ventricular drain was placed first. A diagnostic DSA revealed a $5 \times 3 \mathrm{~mm}$ aneurysm in the Acom (Fig. 1). The aneurysm showed a relatively wide neck, about $3 \mathrm{~mm}$. After a multidisciplinary discussion, the decision was made to perform a balloon-assisted coiling trial first as we try to avoid dual antiplatelet therapy in ruptured cases, and if that is not possible, aneurysm occlusion is performed with stent and coils. During the review of the $3 \mathrm{D}$ rotational reconstructed images, we found that the best possible working view was suboptimal because the aneurysm sac was hidden by the ICA. After placing a SOFIA (6F) Plus distally in the A1 segment, the aneurysm sac could be defined clearly. The A2 segment was catheterized with a Scepter XC balloon and placed in front of the aneurysm's neck. The aneurysm was catheterized with a Headway 17 microcatheter and Traxcess microguidewire. The aneurysm was occluded with 5 coils with a total length of $24 \mathrm{~cm}$. The 
last angiographic control showed that the aneurysm, with a minimal neck remnant, was occluded.

\section{Case 2}

A patient presented with dizziness and fatigue. A non-contrast CT scan and CTA showed an MCA aneurysm on the left side. A diagnostic DSA revealed a wide-neck aneurysm, about 12x13 mm, at the left MCA bifurcation (Fig. 2). Both M2 segments originated from the neck of the aneurysm. After discussion with the patient, the decision was made to perform coiling of the aneurysm assisted with a stent. However, the procedure using our normal approach with a $6 \mathrm{~F}$ guide catheter proximal in the ICA was unsuccessful because it was not possible to catheterize the lower M2 segment as it was hidden by the ICA, and the microcatheter system was unstable because of the tortuosity of the ICA. In the next endovascular treatment session, we used our new technique.
A DIC Catalyst 6F was placed in the proximal M1 segment. Injection into the DIC made the aneurysm sac, neck, and origin of both $\mathrm{M} 2$ segments clearly visible. Y-stenting was done using a Headway Duo microcatheter, while the Headway 17 microcatheter was jailed in the aneurysm. After the stents were placed in their positions, the Catalyst 6F was pulled down in the ICA and the aneurysm was occluded with 10 coils, with a total length of $275 \mathrm{~cm}$. The last angiographic control showed that the aneurysm was occluded and that both $\mathrm{M} 2$ segments were preserved.

\section{Case 3}

A patient presented with acute headache. A non-contrast CT scan showed a widespread SAH, and a CT angiogram revealed an Acom aneurysm consistent with hemorrhage. An external ventricular drain was placed first. A diagnostic DSA revealed a $3 \times 1.4 \mathrm{~mm}$ aneurysm in the Acom (Fig. 3). The
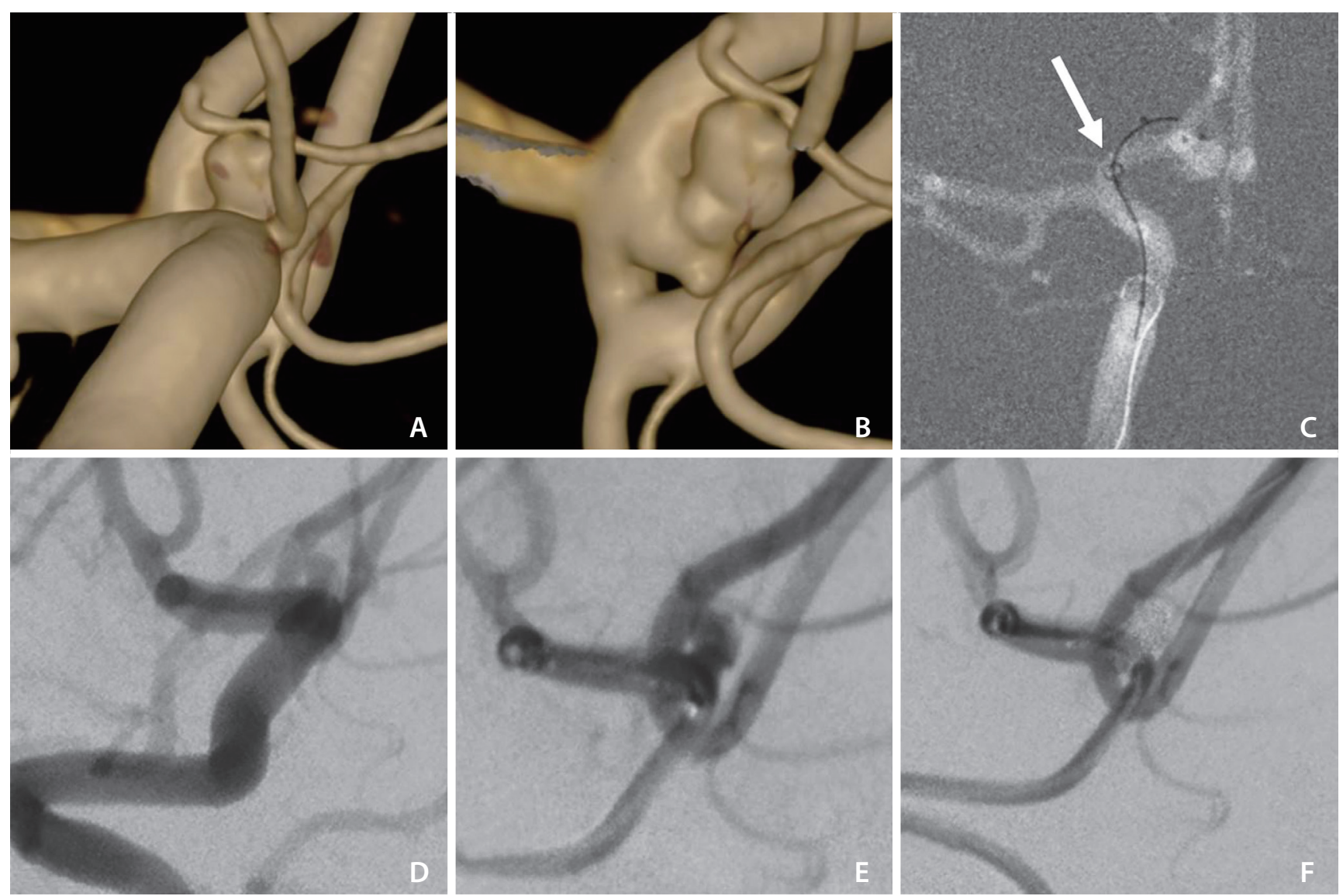

Fig. 1. (A) $3 D$ reconstruction showing the best working view and the aneurysm sac hidden by the ICA. (B) Same working projection after the ICA had been sculpted. (C) DIC tip (arrow) located in proximal A1 segment. (D) Contrast injection into the ICA proximally, showing aneurysm sac hidden by the ICA. (E) Contrast injection into the DIC in the A1 segment with better visualization of aneurysm sac and neck. (F) Post coiling angiographic control demonstrates aneurysm obliteration. 3D, 3-dimensional; ICA, internal carotid artery; DIC, distal intracranial catheter. 
aneurysm showed a relatively narrow neck. The decision was made to perform coiling in the aneurysm. The best working view selected from 3D rotational reconstructed images showed that the aneurysm sac was hidden by the internal carotid artery. After placing a SOFIA 6F Plus distally in the ICA terminus, the aneurysm neck was clearly visible, but not the whole sac. The aneurysm was catheterized with a Headway 17 microcatheter and Traxcess 14 microguidewire. The aneurysm was occluded with a total of 2 coils with total a length of $9 \mathrm{~cm}$. The last angiographic control showed that the aneurysm, with minimal neck remnant, was occluded.

\section{DISCUSSION}

In this report, we present our experience using DICs placed close to an aneurysm in order to obtain good visualization of the aneurysmal sac or the neck. In all our cases, the aneurysmal sac and/or neck was hidden by the internal carotid artery and its branches during the initial angiography. By placing the DIC more distally in the parent artery, close to the aneurysm, we managed to sculpt most of the parent artery and get a clear view of the aneurysm sac or the neck.

A complex aneurysm is described in the literature as a giant aneurysm, an aneurysm with a wide neck, or an aneurysm with 1 or 2 branches originating at the neck or from the aneurysmal sac. ${ }^{15}$ However, sometimes during our work as neurointerventionists, we encounter aneurysms which we consider to be simple aneurysms but which, due to difficulties in obtaining an optimal working view, turn out to be complex and sometimes even endovascularly inoperable.

Traditional guide catheters are relatively stiff in order to pro-
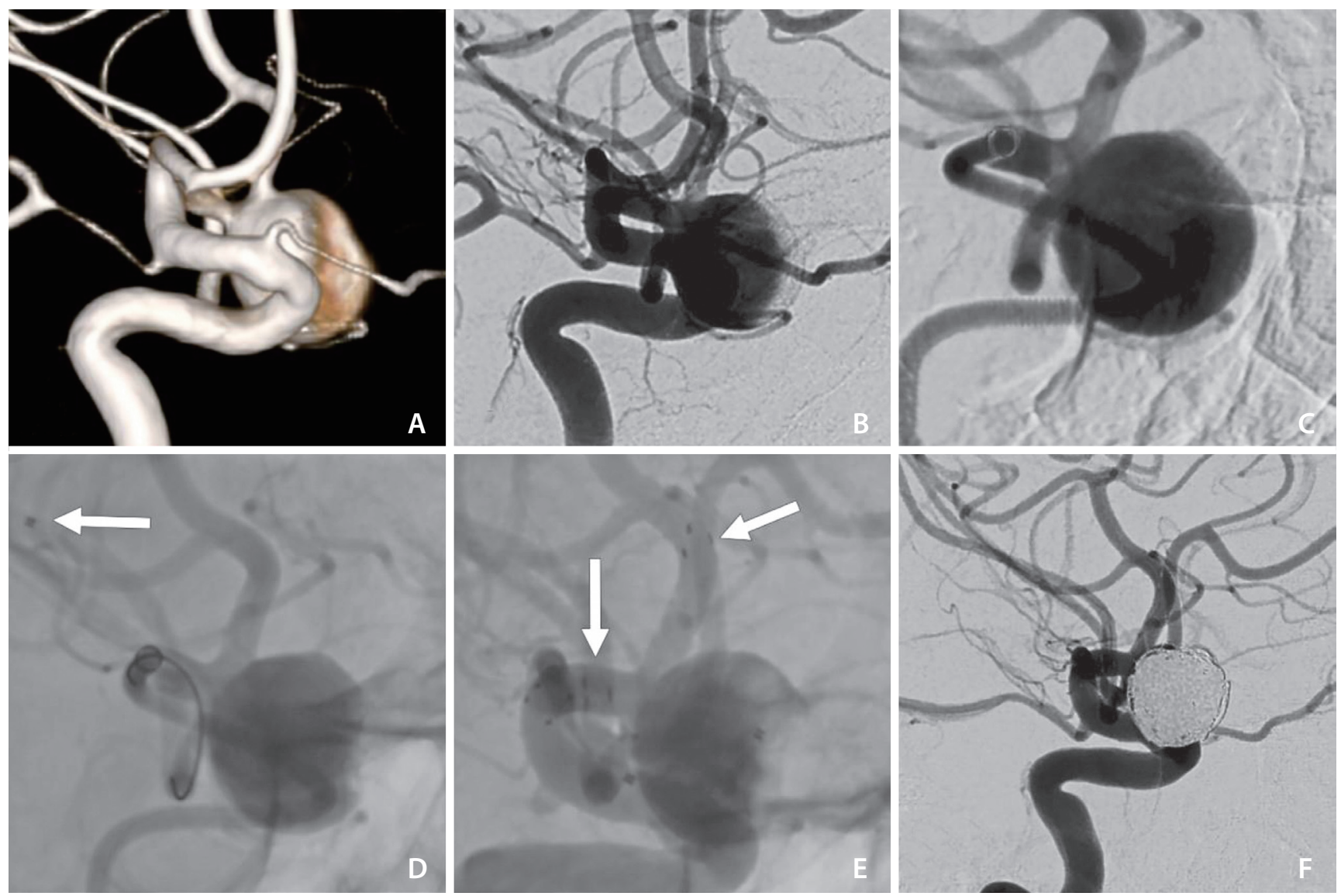

Fig. 2. (A) $3 D$ reconstruction showing the best working view and the neck of the $M C A$ aneurysm and origin of lower $M 2$ segment hidden by the ICA. (B) Contrast injection into the left ICA shows aneurysm neck hidden by the ICA. (C) Contrast injection into the DIC in the M1 segment with better visualization of the aneurysm neck and origin of M2 segments. (D) Microcatheter placed in lower M2 segment (arrow). (E) Angiographic run without subtraction showing both stents in place (arrows) and microcatheter jailed in the aneurysm. (F) Post coiling angiographic control demonstrates obliteration of the aneurysm. 3D, 3-dimensional; MCA, middle cerebral artery; ICA, internal carotid artery; DIC, distal intracranial catheter. 
vide stability, which limits their navigability distally, close to an aneurysm. Advances in guide catheter technology have led to the development of newer guide catheters which are softer, more flexible, and more trackable compared to older models. Several centers have described their experiences with the use of DICs in endovascular treatment of intracranial aneurysms with difficult access to achieve stable and better control of microcatheters during coiling of the cerebral aneurysms. ${ }^{4-13}$ To the best of our knowledge, the advantages of the use of DICs to obtain a better working view and better visualization of the aneurysm have not been described so far.

The DICs we used in the treatment of our patients, SOFIA 6F plus and AXS Catalyst 6, were originally designed to be used for mechanical thrombectomy in the treatment of acute ischemic stroke. ${ }^{16,17}$ In order to enhance the stability of DICs, we used a pentaxial system originally described by Lin et al. ${ }^{18}$ Placement of the DICs in branches of ICA was feasible without catheter-related injuries (dissection or vasospasm). Even though we did not register any catheter-related injuries, the vessel diameter and angle of the A1 or M1 segment should be considered to avoid possible ischemic complications in small diameter vessels and dissection that could occur during forced tracking of the DIC distally.

The transient neurological deficits reported in 3 cases (Table 1) cannot likely be directly attributable to the use of DICs. The transient dysphasia in cases 2 and 5 was caused by minor infarction and subarachnoid bleeding, respectively. In case 4, the transient dysphasia occurred 8 days after the intervention and radiologic examination revealed neither bleeding nor infarction. All patients recovered completely after a couple of days. These complications might have been related to the technique of coiling and stent deployment, or perhaps a toxic effect of the contrast on brain parenchyma in case $5 .{ }^{19}$ Even though we assume that these complications
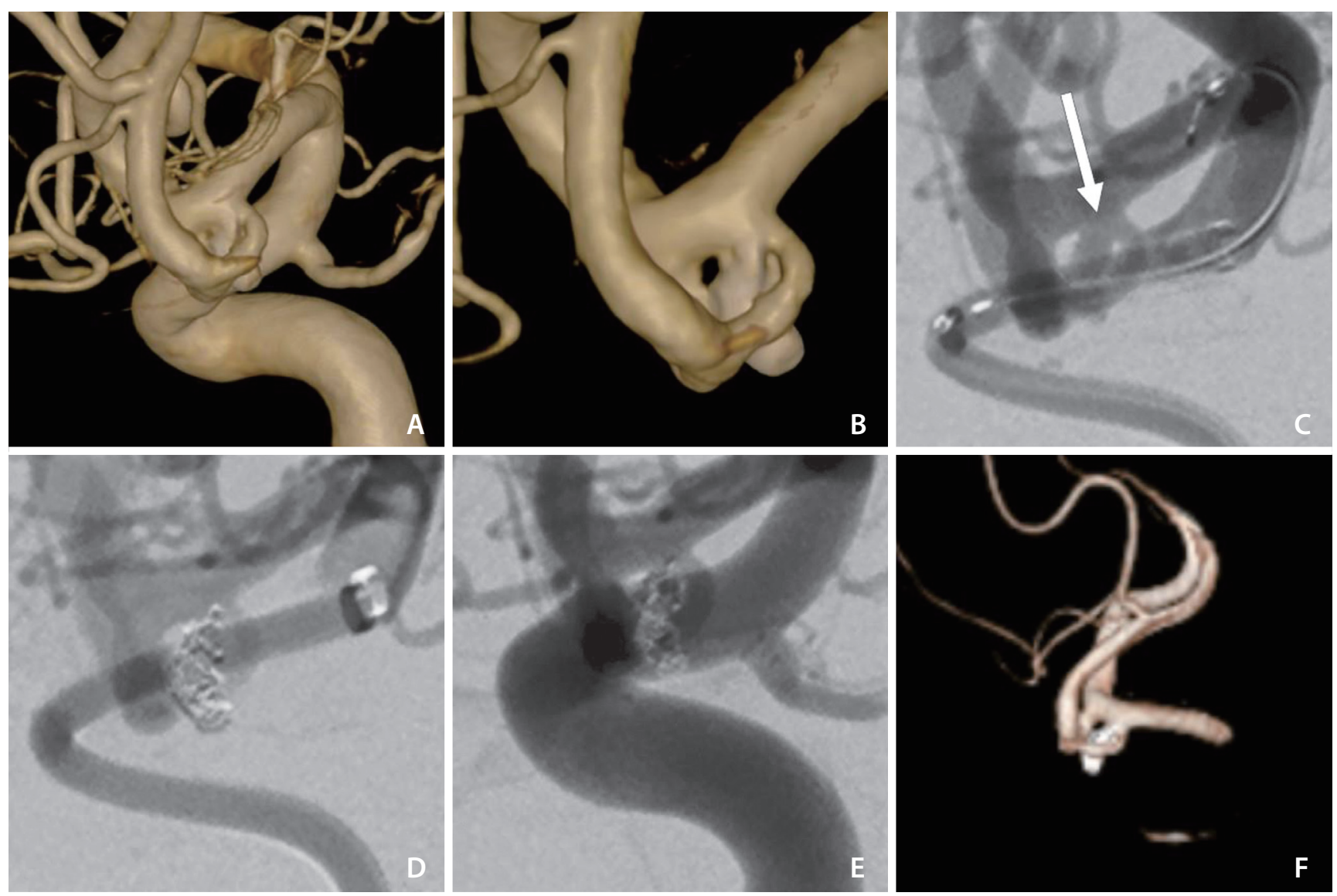

Fig. 3. (A) 3D reconstruction showing the best working view and the Acom aneurysm sac hidden by the ICA. (B) Same working projection after the ICA had been sculpted. (C) Contrast injection into DIC in the carotid terminus showing better visualization of aneurysm sac and neck (arrow). (D) Post coiling angiographic control showing obliteration of the aneurysm. (E) Angiogram obtained by contrast injection into the ICA proximally shows the aneurysm sac hidden by the ICA. (F) Post-coiling 3D reconstruction confirms the obliteration of the aneurysm and preservation of the parent vessels. 3D, 3-dimensional; Acom, anterior communicating artery; ICA, internal carotid artery; DIC, distal intracranial catheter. 
were not related to our technique, we recommend avoiding injections of large amounts of contrast when the DIC is placed in $\mathrm{M} 1$ or A1 segments.

The SOFIA 6F plus and AXS Catalyst 6 were used in conjunction with $6 \mathrm{~F}$ Infinity 0.88 -inch ID, $80 \mathrm{~cm}$ or $90 \mathrm{~cm}$ sheaths, in all cases due to adherence between the long sheath and the DIC, which can reduce the ability to obtain a high-quality roadmap. We recommend obtaining the imaging and/or roadmaps prior to DIC placement.

Since the ID in the AXS Catalyst 6F is 0.60 inches, we experienced some difficulty in obtaining a high-quality roadmap when we used 2 microcatheters, but we did not experience this problem with SOFIA 6F Plus, which has a larger ID of 0.70 inches. However, we suggest a gentle injection of contrast to avoid perforation of the aneurysm, especially in ruptured aneurysms.

We consider the 2 ruptured Acom aneurysms (Figs. 1, 3) in our report endovascularly inoperable without using this technique, as the aneurysm in both cases was small and completely hidden by the parent artery. Despite the treatment procedure (Y-stent and coils) being complex in 2 of the unruptured cases, we experienced a stable microcatheter and a very good working view, which enabled us to catheterize the distal intracranial vessels in an easy and safe way. Finally, using a distally placed DIC was crucial with regard to obtaining a sufficient working projection and providing good support for the microcatheter system.

\section{CONCLUSION}

Using the technique described in this paper, we found it possible to better visualize the aneurysmal sac and/or neck and thereby treat cases we otherwise would have considered untreatable. Although this technique is relatively simple and, in our hands, without serious complications, we recommend reserving this technique for cases that would be difficult or impossible to treat endovascularly without an adequate working view.

\section{Fund}

None.

\section{Ethics Statement}

We confirm that the study was conducted in accordance with Helsinki Declaration as revised in 2013. This manuscript presents technical aspects on neurointerventional procedures, no personal information about the patients was processed. Therefore the project does not require an IRB permission in accordance with the Swedish Ethical Review Authority.

\section{Conflicts of Interest}

The authors have no conflicts to disclose.

\section{Author Contributions}

Concept and design: EM. Analysis and interpretation: EM. Data collection: EM. Writing the article: EM. Critical revision of the article: $E M, S L, C N$, and LB. Final approval of the article: $E M, S L, C N$, and LB. Overall responsibility: EM.

\section{ORCID}

Ehab Mahmoud: https://orcid.org/0000-0002-0820-0280

Samuel Lenell: https://orcid.org/0000-0001-8914-5086

Christoffer Nyberg: https://orcid.org/0000-0003-4388-4267

Ljubisa Borota: https://orcid.org/0000-0001-8190-4252

\section{REFERENCES}

1. Fargen KM, Singh J, Wilson JA, Wolfe SQ. Unassisted aneurysm coil embolization. In: Spiotta AM, Turner RD, Chaudry MI, Turk AS. Management of cerebrovascular disorders: a comprehensive, multidisciplinary approach. Cham: Springer, 2019;143-160

2. Anxionnat R, Bracard S, Ducrocq X, Trousset Y, Launay L, Kerrien E, et al. Intracranial aneurysms: clinical value of 3D digital subtraction angiography in the therapeutic decision and endovascular treatment. Radiology 2001;218:799-808

3. Rossitti S, Pfister M. 3D road-mapping in the endovascular treatment of cerebral aneurysms and arteriovenous malformations. Interv Neuroradiol 2009;15:283-290

4. Lin LM, Colby GP, Huang J, Tamargo RJ, Coon AL. Ultra-distal large-bore intracranial access using the hyperflexible Navien distal intracranial catheter for the treatment of cerebrovascular pathologies: a technical note. J Neurointerv Surg 2014;6:301-307

5. Jindal G, Giacon L, lyoha M, Miller T, Aldrich F, Simard M, et al. Navien catheter experience in neuroendovascular interventions. Interv Neuroradiol 2017;23:551-555

6. Chandran A, Puthuran M, Eldridge PR, Nahser HC. Distal access using hyperflexible atraumatic distal tip with optimized proximal stability of the Benchmark intracranial guide catheter for the treatment of cerebral vascular diseases: a technical note. $J$ 
Neurointerv Surg 2016;8:718-721

7. Hauck EF, Tawk RG, Karter NS, Binning MJ, Khalessi AA, Natarajan SK, et al. Use of the outreach distal access catheter as an intracranial platform facilitates coil embolization of select intracranial aneurysms: technical note. J Neurointerv Surg 2011;3:172-176

8. Binning MJ, Yashar P, Orion D, Hauck EF, Levy El, Hopkins LN, et al. Use of the Outreach Distal Access Catheter for microcatheter stabilization during intracranial arteriovenous malformation embolization. AJNR Am J Neuroradiol 2012;33:E117-E1 19

9. Matsushige T, Sakamoto S, Ishii D, Shinagawa K, Shimonaga K, Hosogai M, et al. Safety and efficacy of a new outreach distal access catheter, TACTICS, for coil embolization of unruptured intracranial aneurysms. Interv Neuroradiol 2018;24:482-488

10. Spiotta AM, Hussain MS, Sivapatham T, Bain M, Gupta R, Moskowitz SI, et al. The versatile distal access catheter: the Cleveland Clinic experience. Neurosurgery 2011;68:1677-1686; discussion 1686

11. Turk A, Manzoor MU, Nyberg EM, Turner RD, Chaudry I. Initial experience with distal guide catheter placement in the treatment of cerebrovascular disease: clinical safety and efficacy. $J$ Neurointerv Surg 2013;5:247-252

12. Lee S, Gong TS, Lee YW, Kim HJ, Kweon CY. The benefits of Navi$\mathrm{en}^{\mathrm{TM}}$ intracranial support catheter for endovascular treatment. J Cerebrovasc Endovasc Neurosurg 2016;18:234-238

13. Chaudhary N, Pandey AS, Thompson BG, Gandhi D, Ansari SA, Gemmete JJ. Utilization of the Neuron 6 French 0.053 inch inner luminal diameter guide catheter for treatment of cerebral vascular pathology: continued experience with ultra distal access into the cerebral vasculature. J Neurointerv Surg 2012;4:301306

14. Mascitelli JR, Moyle H, Oermann EK, Polykarpou MF, Patel AA, Doshi AH, et al. An update to the Raymond-Roy occlusion classification of intracranial aneurysms treated with coil embolization. J Neurointerv Surg 2015;7:496-502

15. Andaluz N, Zuccarello M. Treatment strategies for complex intracranial aneurysms: review of a 12-year experience at the University of Cincinnati. Skull Base 2011;21:233-242

16. Möhlenbruch MA, Kabbasch C, Kowoll A, Broussalis E, Sonnberger M, Müller M, et al. Multicenter experience with the new SOFIA Plus catheter as a primary local aspiration catheter for acute stroke thrombectomy. J Neurointerv Surg 2017;9:12231227

17. Sallustio F, Pampana E, Davoli A, Merolla S, Koch G, Alemseged F, et al. Mechanical thrombectomy of acute ischemic stroke with a new intermediate aspiration catheter: preliminary results. $J$ Neurointerv Surg 2018;10:975-977

18. Lin LM, Colby GP, lyer RR, Jiang B, Huang J, Tamargo RJ, et al. Pentaxial access platform for ultra-distal intracranial delivery of a large-bore hyperflexible DIC (distal intracranial catheter): a technical note. Interdiscip Neurosurg 2016;6:29-34

19. Harada Y, Kairamkonda SR, Ilyas U, Pothineni NVK, Samant RS, Shah VA, et al. Pearls \& Oy-sters: contrast-induced encephalopathy following coronary angiography: a rare stroke mimic. Neurology 2020;94:e2491-e2494 